\title{
On the analysis of spelling errors. Causes, correspondence rules, and variation in pronunciation
}

\author{
HOLGER JUUL AND JAN HEEGÅRD PETERSEN
}

\begin{abstract}
ABSTRAC'T
This paper illustrates how spelling errors can be analyzed in a didactically relevant manner, and it draws attention to knowledge about pronunciation as an indispensable tool in this task. A basic distinction is made between norm conflicts and norm gaps as two causes for spelling errors. Deviation from a distinct, standard language pronunciation ('rigsmål') may cause norm conflict errors, whereas lack of knowledge about letter-to-sound correspondence may cause norm gap errors. Such norm gap errors may further be divided into four types according to whether they concern unconditioned rules, pronunciation conditions, grammatical conditions, or lexical conditions. The typology of causes for spelling errors and the illustration of the correspondence rules are followed by a survey of some more recent phonetic developments in Standard Danish that may cause more difficulties in the spelling process. The papers ends with a discussion of whether political, technological, and didactic initiatives can make Danish spelling easier.
\end{abstract}

KEYWORDS: language norms; correspondence rules; orthography; sound development 